\title{
GÊNEROS TEXTUAIS E LÍNGUA INGLESA EM USO: UMA ANÁLISE DAS COLEÇÕES APROVADAS PELO PNLD/LE NO BRASIL
}

\author{
TEXT GENRE AND ENGLISH LANGUAGE IN USE: \\ AN ANALYSIS OF THE TEXTBOOKS APPROVED BY THE \\ BRAZILIAN GOVERNMENT (PNLD/LE)
}

\section{Ana Larissa A. M. Oliveira*}

\section{RESUMO}

Este artigo tem como objetivo analisar dois livros de inglês aprovados no Programa Nacional do Livro Didático (PNLD/LE/2011) para o Ensino Fundamental II nas escolas públicas brasileiras, comparando-as com outras duas coleções, publicadas em período anterior ao documento, e bastante utilizadas nas escolas brasileiras. A análise aqui apresentada centrase na abordagem dos gêneros textuais orais e escritos presente nestas obras, uma vez que essa abordagem encontra-se no cerne da proposta de incorporar uma visão de ensino de LE centrada na língua em uso, como prática social. Os resultados demonstraram uma tendência positiva de mudança, resultante da inserção das línguas estrangeiras no PNLD. Essa tendência poderá compor um novo domínio discursivo para o livro didático de língua estrangeira brasileiro, incluindo a reafirmação dos conceitos de gênero textual, tipo textual, oralidade e escrita, por muito tempo, bastante negligenciados.

Palavras-chave: gênero textual; língua em uso; oralidade e escrita.

\section{ABSTRACT}

This article aims at analyzing the two English textbooks approved by the National Textbook Program (PNLD/LE/2011) in Brazil. They have been compared to two other textbooks, published in the period prior to the implementation of the Program, and very widely used in Brazilian schools. The present analysis focuses on the spoken and written text genres of the textbooks in focus, since this pedagogical approach lies at the heart of the proposal to incorporate language in use as social practice in the teaching of English. The results showed a trend of positive change, after foreign languages textbooks were incorporated in the National Textbook Program. This trend can help reshape the discourse domain of English textbooks in Brazil, which includes the concepts of text genre and text type, in spoken and written language, which had been neglected for some time.

Keywords: text genre; language in use; orality and writing.

\footnotetext{
"UFMG/FALE, Belo Horizonte (MG),Brasil. a-larissa@uol.com.br
} 


\section{INTRODUÇÃO}

O tema da formação de professores de línguas estrangeiras (LE) no Brasil tem sido amplamente debatido por pesquisadores da área, principalmente a partir do final dos anos 90, quando também começaram a se consolidar no País as parcerias entre universidade e escola básica, desenvolvidas por várias universidades brasileiras, entre elas, o LAEL (PUC-SP), a FALE (UFMG) e o IL (UEL), apenas para citar algumas. Essas iniciativas visam, principalmente, à formação continuada dos professores de LI (Língua Inglesa), por meio de sua requalificação teóricometodológica e linguística. Apesar dos bons resultados destes projetos, divulgados por meio de trabalhos de mestrado e doutorado nas publicações da área (JESUS, MELLO e DUTRA, 2007), o trabalho de formação continuada revela muita preocupação quanto à formação básica do professor de Letras. Essa constatação levou Cox (2010, p. 15), a intitular a formação continuada de "cosmética". A autora visava, por meio do epíteto, chamar a atenção para a necessidade de fortalecer os cursos de licenciatura no Brasil que, de acordo com ela, nem sempre formam professores capazes, por exemplo, de implantar as políticas públicas para o ensino de línguas determinadas pelos documentos oficiais do País.

Essas políticas, no caso das LEs, postulam um ensino integrado das quatro habilidades linguísticas, com ênfase em aspectos comunicativos e críticos. Desse modo, o ensino de uma LE deve, de acordo com os documentos oficiais, não apenas instrumentalizar o aluno para usar a língua em diferentes esferas sociais, mas também enfatizar, permanentemente, o caráter educativo da disciplina, garantindo uma formação cidadã e plural.

Dentre essas políticas, destaca-se o Programa Nacional do Livro Didático (PNLD), que é o mais antigo dos programas voltados à distribuição de obras didáticas aos alunos da rede pública de ensino brasileira, tendo sido iniciado, com outro formato e denominação há várias décadas. Em sua configuração atual, o programa atendia, até 2010, aos alunos nas áreas de língua portuguesa, matemática, ciências, história, geografia e também distribuía obras literárias.

Em 2011, a área de LE passou a ser também compreendida pelo programa e os alunos da rede pública brasileira passaram a receber livros de Inglês e Espanhol, acompanhados de CD de áudio. Acerca da inclusão das LEs no PNLD, o Guia de Coleções, publicado pelo MEC, afirma sua importância para a formação do cidadão da seguinte maneira: 


\begin{abstract}
Apesar de o PNLD já existir há mais de dez anos, esta é a primeira vez que ele inclui o componente curricular Língua Estrangeira Moderna (LEM ${ }^{1}$ ): Espanhol e Inglês. Trata-se, portanto, de um momento importante na história do ensino de LEM nas escolas públicas brasileiras, que reflete um reconhecimento do papel que esse componente curricular tem na formação dos estudantes (Guia de Coleções PNLD/LE 2011, disponível em: HTTP://www.portal.mec.gov.br, acesso em fev, 2011).
\end{abstract}

A iniciativa representa, de fato, passo importante no ensino de LE, uma vez que as políticas públicas para a área no Brasil sempre foram ineficientes ou ausentes. Acerca disso, Cox e Assis-Peterson (2009), em amplo artigo sobre o tema, discutem o "drama do ensino de Línguas Estrangeiras no Brasil" que, historicamente, sempre resultou na exclusão dos mais pobres do processo de aprendizagem. Decorre disso a crença, ainda muito presente no Brasil, de que é "impossível aprender Inglês na escola pública".

Tendo em foco a importância da primeira edição do PNLD/LE para a formação linguística dos alunos da escola pública brasileira, este trabalho centra-se na análise de quatro coleções didáticas de língua inglesa (C1, C2, C3 e C4), cada uma contendo quatro volumes, voltados para o Ensino Fundamental II, ou seja, do sexto ao nono ano escolar brasileiros. As coleções $\mathrm{C} 1$ e $\mathrm{C} 2$ foram selecionadas por estarem na lista das mais vendidas no Brasil para escolas particulares, já que, nas escolas públicas, os livros didáticos de LE não eram tradicionalmente adotados, devido à falta de recursos dos alunos e à ausência de investimento do governo na área. Os professores trabalhavam, quase sempre, com quadro, giz e cópias, quando disponíveis. Quanto às coleções C3 e C4, aqui também analisadas, elas foram selecionadas por terem sido as duas únicas coletâneas aprovadas pelo PNLD, mediante um total de 23 obras submetidas ao primeiro Edital.

Para empreender os objetivos aqui propostos, quais sejam, analisar a abordagem de gêneros textuais nas duas coleções aprovadas pelo PNLD/LE 2011 em contraste com duas obras produzidas anteriormente ao Edital do programa, este texto está divido em quatro partes. Na primeira, há um breve panorama das políticas para o ensino de LE no Brasil, com destaque para o PNLD/LE. Na segunda seção são definidos tipos e gêneros textuais de acordo com Marcuschi (2009). Na terceira seção, serão elencados os resultados das análises de duas coleções anteriores ao programa, juntamente com um apanhado teórico sobre o tema. Na quarta seção, serão apresentadas as análises das coletâneas constituintes do PNLD/2011 em contraste com as duas obras produzidas anteriormente ao Edital, para, finalmente, serem tecidas considerações

1. LEM: Línguas estrangeiras modernas. 
com o propósito de conectar as políticas públicas para o livro didático e a formação docente inicial no Brasil.

A análise apresentada neste texto centra-se na abordagem dos gêneros textuais orais e escritos presente nas obras selecionadas. A razão desse recorte justifica-se pelo fato de que o tema é significativo para a área de formação de professores de LE, principalmente após a edição dos $\mathrm{PNCNs/LE}$, nos anos 90 do século XX. A abordagem pedagógica dos gêneros textuais encontra-se, também, no cerne da proposta de incorporar uma visão de ensino de LE centrada na língua como prática social, destacada em todos os documentos oficiais brasileiros da área.

Quanto ao trabalho com textos orais e escritos, o Edital do PNLD apresenta, no item IX, relativo aos critérios para a seleção das obras, os fundamentos dessa teoria, explicitado por meio de nove perguntas de avaliação das obras, apresentadas a seguir:

Coletânea de textos orais e escritos

São apresentados textos representativos de diferentes esferas de atividade social?

São apresentados textos de tipos e gêneros diferentes?

São apresentados textos não verbais e textos que integram as modalidades verbal e não-verbal?

Os textos apresentam diversidade de suportes originais (revistas, almanaques, jornais, sítios da internet, periódicos científicos etc.)?

Os textos contemplam a produção cultural específica para jovens e adolescentes?

Os temas dos textos contribuem para a ampliação dos horizontes culturais do aluno?

Os textos são, em sua maioria, autênticos (isto é, circulam socialmente na cultura oral e escrita) e, se autorais, trazem a indicação da fonte de origem?

Os fragmentos e adaptações mantêm unidade de sentido, trazendo indicação dos cortes realizados?

In: (Guia de Coleções PNLD/LE 2011, disponível em: HTTP://www.portal.mec.gov. br, acesso em Fev, 2011).

\section{ABORDAGEM PEDAGÓGICA DOS GÊNEROS TEXTUAIS: UM BREVE PANORAMA TEÓRICO}

A importância de enfatizar a linguagem como prática social no ensino de uma LE tem sido largamente reconhecida, principalmente depois dos anos 90, quando os 
estudos sobre os gêneros textuais tornaram-se mais divulgados no Brasil por meio, principalmente, da edição dos Novos Parâmetros Curriculares Nacionais (PCNs) para o ensino de língua materna e de língua estrangeira, conforme já apontado anteriormente neste texto.

Nessa abordagem, reside a noção central de que as práticas sociais humanas envolvem sempre o uso da linguagem. Elas precisam, portanto, ser entendidas como atividades sociais, histórica e ideologicamente constituídas, além de localmente situadas. Por isso, nas aulas de LE, é necessário repensar, por exemplo, as práticas de repetição ou de reprodução de modelos, cristalizadas pelo audiolingualismo, e inserir o aluno em contextos reais de uso da LE com base em uma perspectiva enunciativa, ou seja, voltada para os aspectos comunicativos e persuasivos da linguagem.

Desse modo, na perspectiva do trabalho pedagógico com gêneros textuais, para que um discurso se constitua, relacionam-se, necessariamente, um falante, um determinado contexto (histórico, social, cultural e ideológico) e um objetivo comunicativo. São esses os elementos constitutivos da organização do discurso, seja ele escrito ou oral. Em decorrência disso, as comunicações humanas tendem a seguir certos padrões pré-estabelecidos sócio-historicamente, caso contrário os falantes não se entenderiam. Assim sendo, tais padrões constituem-se em gêneros textuais diferentes. O conhecimento desses padrões é, ao mesmo tempo, uma força libertadora, pois insere o falante em uma comunidade linguística, legitimando sua participação nesta e, também, um artefato cultural modelador, já que o compele a seguir as convenções linguísticas específicas de cada contexto discursivo.

Dessa maneira, verifica-se que não há comunicação fora da esfera dos gêneros textuais, assim como não existe gênero textual sem que se pressuponha um texto oral ou escrito (BAKHTIN, 1997; HALLIDAY, 2004; e MARCUSCHI, 2003). Essa relação de interdependência de texto e esfera comunicativa aponta também para a necessidade de compreender a língua por seu aspecto funcional, bem como por sua estrutura formal, já que ambas apresentam relação interfacial. Diante disso, Marcuschi (2003) define os gêneros textuais "como as entidades comunicativas pelas quais o discurso se realiza" (MARCUSCHI 2003, p. 16). Elas compreendem os diferentes artefatos culturais (BAKHTIN, 1997), consubstanciados por meio de textos orais e escritos, que circulam na vida social. Além disso, por serem fruto de trabalho individual (do falante) e coletivo (da sociedade e da cultura) ao mesmo tempo, os gêneros textuais são entidades discursivas, sócio-historicamente estabelecidas. Eles se constituem, portanto, em um importante objeto de estudo nas aulas de LE, especialmente no que diz respeito à leitura crítica e à produção de textos orais e escritos socialmente relevantes. 
O trabalho com gêneros textuais no ensino de uma LE aumenta a consciência linguística do aprendiz, permitindo seu engajamento e atuação social nas comunidades nas quais ele se insere, já que se constitui de material autêntico, presente na vida social e, por isso, habilitado a extrapolar a soleira da porta da sala de aula.

Uma vez presentes nas interações sociais humanas cotidianas de todas as comunidades, independentemente da língua compartilhada, o estudo das configurações linguísticas dos gêneros textuais e suas funções comunicativas contribui para a consciência, desenvolvimento e consequente uso das estratégias comunicativas dos alunos.

Do ponto de vista pedagógico, a apresentação dos gêneros segue, quase sempre, os seguintes passos: leitura e compreensão de textos de exemplares de um certo gênero; discussão do contexto de produção e da intenção comunicativa; análise da função comunicativa do texto; identificação das principais características linguísticas e do registro; análise dos tipos textuais que compõem o gênero; atividades de produção oral e escrita com base no gênero em foco (OLIVEIRA \& LOPEZ, 2010). A esse respeito, a seção seguinte discute algumas distinções que, acreditamos, sejam importantes na abordagem de gêneros textuais na sala de aula de LE.

\section{TIPOS TEXTUAIS E GÊNEROS TEXTUAIS: DEFINIÇÕES DE BASE NO ESTUDO}

Este estudo coaduna-se com a distinção de tipo e gênero textual conforme proposta por Marcuschi (2009, p. 27). De acordo com o autor, os tipos textuais:

- são definidos por propriedades linguísticas intrínsecas, identificadas por meio de elementos sintáticos e lexicais, por exemplo;

- constituem sequências linguísticas ou sequências de enunciados e não são textos empíricos, encontrados na prática comunicativa real,

- sua nomeação abrange um conjunto limitado de categorias teóricas determinadas por aspectos lexicais, sintáticos e formas verbais;

- pertencem às designações teóricas dos tipos: narração, argumentação, descrição, injunção e exposição.

De modo semelhante, no que ser refere à categorização dos gêneros textuais, os seguintes aspectos são assinalados por Marcuschi (2009, p. 19) com respeito à definição de gêneros textuais: 
- são realizações linguísticas empíricas, definidas por propriedades sóciocomunicativas;

- sua nomeação abrange um conjunto aberto e praticamente ilimitado de designações concretas determinadas pelo canal, estilo, conteúdo, composição e função comunicativa do texto;

- exemplos de gêneros: telefonema, sermão, mensagem de e-mail, romance, bilhete, aula expositiva, reunião de condomínio, horóscopo, receita culinária, bula de remédio, lista de compras, bate-papo virtual.

Tendo isso em vista, a análise da abordagem pedagógica dos gêneros textuais aqui descrita também requer a discussão teórica acerca da definição de domínio discursivo. Para Marcuschi (2009), o domínio discursivo refere-se à esfera de produção discursiva ou de atividade humana. Assim, os domínios discursivos não são nem textos nem discursos, mas propiciam o surgimento de discursos bastante específicos. Desse modo, podemos falar em discurso jurídico, discurso jornalístico, discurso religioso, discurso pedagógico, por exemplo. Esses domínios constituem práticas discursivas dentro das quais podemos identificar um conjunto de gêneros textuais que, às vezes, lhe são próprios (em certos casos, exclusivos) como práticas ou rotinas comunicativas institucionalizadas em algum gênero textual.

A partir deste, observaremos, nas seções seguintes, os novos domínios discursivos nos quais a abordagem pedagógica dos gêneros textuais pode ter inserido o livro didático brasileiro de língua estrangeira após seu ingresso no PNLD, a partir de 2011 .

\section{A ABORDAGEM DOS GÊNEROS TEXTUAIS: DISTINÇÕES NECESSÁRIAS}

Conforme a teoria dos gêneros textuais foi sendo divulgada no Brasil, mais LDs passaram a utilizá-la em suas abordagens pedagógicas. O movimento, entretanto, foi povoado por algumas incertezas e mal-entendidos. $\mathrm{O}$ primeiro deles refere-se à crença de que gêneros textuais e, por consequência os textos em geral, referem-se sempre à forma escrita da língua. A esse respeito é importante notar que o mito da supremacia da escrita esteve sempre muito presente na escola, principalmente porque este é seu principal modo de construção e socialização do saber. $\mathrm{O}$ caráter documental da escrita gerou, entre outros, o mito de que a forma textual escrita é superior, mais organizada e mais elaborada do que a forma textual oral. Vários linguistas têm recentemente contribuído para lançar luz sobre o tema, entre eles, Marcuschi (2009) e Perini (2010) que nos mostram, analiticamente, a 
complexa composição do texto oral. Esses autores também ajudam a compreender que o universo da escrita e o da fala, apesar de distintos entre si, contém pontos de intersecção, sendo, assim, parte de um mesmo continuum, o que observamos, por exemplo, nos fenômenos de hibridismo identificáveis em bilhetes e mensagens de correio eletrônico, entre outros. A esse respeito, na $\mathrm{C} 1$, de acordo com o manual do professor, diferentes gêneros textuais são analisados, como se vê no Excerto 1, abaixo:

\section{Excerto I}

"A obra objetiva contato com variados gêneros textuais, bem como, deferentes tarefas de compreensão e produção escrita"

C1

O mito da superioridade linguística da palavra escrita é, contudo, exemplificado a seguir, na $\mathrm{C} 1$, não pertencente ao programa do PNLD, como já notificado anteriormente neste texto.

Nessa obra, o reconhecimento do texto oral como unidade complexa de produção de sentido é ausente ou muito reduzido. Esse distanciamento é justificado no material, em vários outros momentos, pela ênfase no texto escrito, sem praticamente nenhuma menção ao texto oral.

De todo modo, a abordagem com o texto escrito também apresenta equívocos, bem como importantes erros conceituais e insuficiências teóricas referentes às definições de "texto", "gênero textual" e "tipo textual". Essa insuficiência revela-se no Excerto II, a seguir, também retirado do manual do professor da $\mathrm{C} 1$, em que a distinção entre tipo e gênero textual não é clara, apesar de o referido manual apresentar, em vários momentos, a teoria dos gêneros textuais como sua base teórico-metodológica principal.

\section{Excerto II}

"Para o trabalho com gêneros textuais, buscamos variedades de tipos de textos, tais como: carta, mensagens de e-mail, panfletos turísticos" (C1)

No que concerne à compreensão escrita dos gêneros textuais em foco, os exercícios propostos na $\mathrm{C} 1$ e $\mathrm{C} 2$ apresentam, com frequência, um texto escrito, 
supostamente autêntico ${ }^{2}$, seguido de exercícios centrados na localização de informações.

A esse respeito, na $\mathrm{C} 2$, por exemplo, uma das unidades, prototípica das demais, traz um texto em forma de anúncio imobiliário. A abordagem deste texto não contempla as estratégias de leitura coerentes com esse gênero em questão, pois a atividade limita-se a pedir que o aluno complete frases copiando do texto a descrição do mobiliário e dos cômodos de uma dada casa. Além disso, embora a unidade apresente uma temática propícia ao desenvolvimento do pensamento crítico, relativa à questão da habitação, verifica-se apenas a ocorrência de atividades mecânicas, de completar espaços, que buscam reforçar o conteúdo gramatical e vocabular em tela na unidade, neste caso, o presente simples. Diante disso, o trabalho com a língua fica restrito ao âmbito sentencial, sem atingir o âmbito textual ou comunicativo propriamente dito.

Outro aspecto saliente na análise da $\mathrm{C} 1$ e da $\mathrm{C} 2$ refere-se ao fato de que ambas apresentam textos propostos para fins didáticos específicos, normalmente não-autênticos, destinados ao treino de estruturas gramaticais e de itens lexicais específicos. Não há, pois, nessas duas coleções, uma articulação clara entre os modelos teóricos mencionados no manual do professor, que abordam a teoria dos gêneros textuais, e o conteúdo efetivamente proposto no livro do aluno.

De outra feita, em algumas unidades, os textos escritos das coleções visam a representar diferentes gêneros e tipos textuais, no entanto, esses textos, por terem sido criados para fins didáticos, não estão acompanhados de suas fontes bibliográficas e, nem sempre, é possível identificar o suporte em que podem ser encontrados.

Mais frequentemente ainda, na $\mathrm{C} 1$ a $\mathrm{C} 2$ alguns textos são supostamente representantes de um determinado gênero, principalmente digital. Eles apresentam, assim, o layout de uma página semelhante a uma página da internet, no entanto, não trazem nenhuma indicação precisa de fonte bibliográfica ou digital, também não informando o sítio e data de acesso da à página. Observa-se, desse modo, que a C1 e a C2 não consideram os portadores textuais ou as condições de produção dos textos como produtores de sentido, ou o fazem de modo insuficiente.

Finalmente, retomando em parte o que já se discutiu até aqui, a maioria dos textos apresentados na $\mathrm{C} 1$ e na $\mathrm{C} 2$ são adaptados ou autorais. Criados para fins didáticos, eles são acompanhados de exercícios para localização de informação no texto e para prática de itens gramaticais e de vocabulário específicos. Como se vê,

$2 \mathrm{O}$ termo material autêntico, neste estudo, refere-se a textos que circulam na vida social e se tornam objeto de ensino-aprendizagem de línguas. 
a abordagem baseada na teoria dos gêneros textuais é apenas citada no manual do professor, provavelmente em decorrência das demandas dos documentos oficiais da área, e não efetivamente aplicada no livro do aluno.

$\mathrm{Na}$ mesma direção, na $\mathrm{C} 1$ e na $\mathrm{C} 2$, as atividades de compreensão de leitura e escrita não consideram as convenções e os modos de ler constitutivos de diferentes gêneros e tipos textuais e não ressaltam o caráter polifônico e a multiplicidade de vozes presentes nos textos. Na maioria das atividades, a leitura é usada como pretexto para a abordagem de questões gramaticais e a oralidade não é tratada como constituída de textualidade. A seguir, serão analisadas as obras aprovadas no PNLD/2011, com vistas ao aspecto textual. Estaremos caminhando rumo a um maior entendimento do tema?

\title{
4. AS OBRAS SELECIONADAS PELO PNLD/LE 2011: OTIMISTAS PREVISÕES?
}

Nas duas coleções aprovadas pelo PNLD/LE, C3 e C4, conforme consta no próprio Guia do Livro Didático houve muitos avanços, principalmente no que concerne ao ensino contextualizado de gramática e de vocabulário. O conceito de texto permanece, no entanto, ainda fortemente vinculado ao formato escrito, principalmente na $\mathrm{C} 4$. $\mathrm{Na} \mathrm{C} 3$, a integração entre a abordagem de gêneros e o ensino das habilidades orais e escritas é mais evidente. A esse respeito, sobre a C3, por exemplo, o Guia afirma:

\begin{abstract}
A compreensão escrita é tratada nas seções Get in the mood, Presentation e Let's read. Diferentes linguagens, gêneros e tipos textuais são efetivamente trabalhados em atividades que incluem pré e pós-leitura e o desenvolvimento de várias estratégias. Os mecanismos de coesão e coerência são, por vezes, enfocados. Além disso, alunos e professores são estimulados a buscar textos e informações fora do livro didático (Guia da Coleção PNLD/LE 2011, disponível em: HTTP://www.portal.mec.gov.br, acesso em 05/02/ 2011)
\end{abstract}

Em relação à proposta de ensino comunicativo da língua inglesa, a C3 apresenta uma convergência entre a proposta de ensino comunicativo, que trabalha as quatro habilidades linguísticas, e as concepções contemporâneas de ensino de línguas, direcionadas ao aspecto discursivo e textual da LI. Para isso, a C3 incorpora adequadamente conceitos como "tipos" e "gêneros" textuais, tanto no manual do professor quanto no livro do aluno. Nota-se, também, nas unidades, uma preocupação em tornar a sala de aula de inglês uma instância de reflexão acerca de temas socialmente relevantes. 
Desse modo, a C3 apresenta textos orais e escritos da esfera cotidiana, tais como: diálogos rotineiros, email, documentos pessoais, provérbios, citações, matérias enciclopédicas, agenda de telefone, formulário, lista de convidados, convites, cartões de felicitação, avisos, bilhetes, anúncios, programa de reciclagem, descrição das cores primárias e secundárias, quadrinhos, cartazes, piadas e poemas. Há também algumas seções destinadas à ampliação dos conhecimentos dos alunos quanto aos gêneros textuais presentes na comunicação oral e escrita.

Com respeito à C4, também aprovada pelo PNLD/LE 2011, constata-se menor solidez e/ou profundidade quanto ao tratamento dado aos gêneros textuais, pois, de acordo com o próprio Guia:

\begin{abstract}
As atividades de compreensão escrita são trabalhadas na seção Let's Read, com textos que introduzem o tema a ser discutido. Os textos utilizados nas atividades de leitura são, em sua maioria, elaborados especificamente para fins didáticos. Apesar de haver um empenho em caracterizar esses textos como pertencentes a gêneros, tipos e suportes midiáticos variados, raramente proporcionam ao aluno oportunidades de usar a língua de forma contextualizada ou de aprender sobre os modos de ler constitutivos dos gêneros específicos (Guia da Coleção PNLD/LE 2011, disponível em: HTTP:// www.portal.mec.gov.br, acesso em 05/02/ 2011).
\end{abstract}

$\mathrm{Na} \mathrm{C} 4$, a referida seção, intitulada "Let's read", destinada à proposta de trabalhar o reconhecimento sobre os gêneros textuais, há considerável diversidade destes: posters, murais, cardápios, páginas de internet, entrevistas, álbum de fotografia, tabela de informações, quadrinhos e folheto turístico. Entretanto, os textos foram todos escritos com fim pedagógico e são simulacros de textos que circulam na vida cotidiana. Por essa razão, os suportes textuais não podem ser facilmente identificados e perdem seus elementos não-verbais, bem como os demais portadores textuais. Embora muitos textos orais e escritos tenham relevância para a formação lingüística do aluno e apresentem possibilidades de aplicação do conteúdo em foco na unidade, a maior parte deles apresenta apenas verossimilhanças com os extratos que circulam socialmente, impedindo, assim, o acesso do aluno a situações concretas de uso da LI.

\title{
CONSIDERAÇÕES FINAIS
}

A análise das coleções aqui apresentada aponta para um caminho de mudança no domínio discursivo do livro didático brasileiro de língua estrangeira. No que concerne à abordagem pedagógica da teoria dos gêneros textuais, foi constado um 
enriquecimento do trabalho com gêneros nas duas coleções aprovadas pelo PNLD, especialmente na C3. Esse tratamento é significativamente diferente daquele presente nas coleções publicadas anteriormente ao Edital, o que assinala o alcance de políticas públicas sérias, destinadas ao ensino lingüístico público, quando estas são efetivamente implementadas.

De outra feita, embora ainda permaneçam na $\mathrm{C} 2$ e na $\mathrm{C} 3$ alguns mitos e concepções simplificadas, principalmente relativas à superioridade irrestrita do texto escrito, parece haver uma tendência positiva de amadurecimento teóricometodológico da parte dos autores de livros didáticos no Brasil que começa a se delinear agora.

A constatação compele-nos, mais uma vez, a chamar a atenção para a formação básica do professor de línguas que, entre outras atribuições, precisa prepará-lo para atuar como um analista da linguagem, capaz de perceber os variados modos pelos quais os seres humanos produzem significado, representam o mundo e interagem na forma de palavras. Fazendo, assim, uso crítico e independente das obras didáticas a seu alcance.

Resta-nos, mais ainda, continuar a observar atentamente outros movimentos políticos voltados para a área docente e aguardar que, entre eles, finalmente figure uma maior valorização econômica e social daqueles que, como afirma a escritora brasileira Ana Miranda (2010): "são as pessoas mais importantes do mundo".

\section{REFERÊNCIAS BIBLIOGRÁFICAS}

BAKHTIN, M. (1977). Os gêneros do discurso. Estética da criação Verbal. 2. ed. São Paulo: Martins Fontes.

BRASIL (MEC). Guia Nacional do Livro Didático/2011. Disponível em: http://www.portal.mec. gov.br. Acesso em: fev. 2011.

COX, M. I. P.; ASSIS-PETERSON, A. A. (2008). O drama do ensino de inglês no Brasil. In: ASSIS-PETERSON, A. A. Línguas estrangeiras: para além do método. São Carlos: Pedro \&João Ed./Cuiabá: EdUFMT, p. 97-113.

COX, M. I. P. (2010). Quem tem medo do Latim? In: ASSIS-PETERSON, A. A; BARROS, S. (Org.). Formação crítica de professores de línguas: desejos e possibilidades. São Paulo: Pedro e João Ed.

HALLIDAY M. A. K. Halliday An introduction to functional grammar. rev. ed. London: Hodder Arnold Publication, 2004.

JESUS, A.; MELLO, H.; DUTRA, D. (2007). Reflective collaborative partnership enlightening new classroom practices. In: Language teacher research in the Americas. McGarrell, H. (Ed.). TESOL Publications, p. 209-217. 
MARCUSCHI, L. A. Gêneros textuais: definições e funcionalidade. Disponível em: http:// www.proead.unit.br/professor/linguaportuguesa/arquivos/textos/Generos textuias definicoes funcionalidade.rtf. Acesso em: 2 dez. 2009.

MIRANDA, A. (2010). Texto jornalístico. Revista Caros Amigos, out.

OLIVEIRA, A. L. A. M. (2010). Gêneros textuais orais e escritos no ensino de português como língua estrangeira: um estudo colaborativo em situação de formação docente inicial. Anais do IV CIELLI.

PERINI, M. (2010). Gramática do português brasileiro. São Paulo: Parábola Editorial.

Recebido: 03/11/2011

Aceito: 02/04/2012 
